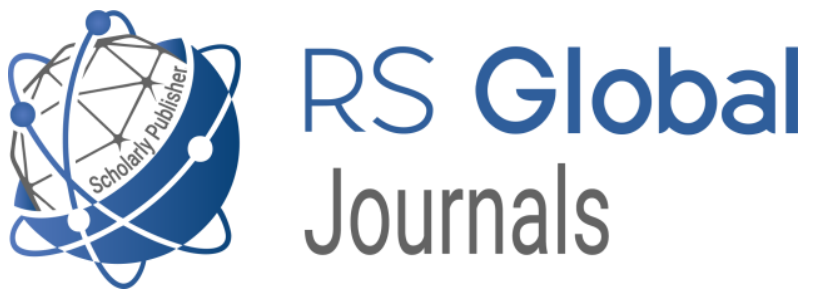

Scholarly Publisher

RS Global Sp. z O.O.

ISNI: 0000000484952390

Dolna 17, Warsaw, Poland 00-773

Tel: +48226022703

Email: editorial_office@rsglobal.pl

JOURNAL International Journal of Innovative Technologies in Social Science

p-ISSN

2544-9338

e-ISSN

2544-9435

PUBLISHER

RS Global Sp. z O.O., Poland

ARTICLE TITLE LEXICAL POLYSEMY IN THE COMPARATIVE

THE INVESTIGATION OF THE GRAMMATICAL AND LANGUAGES

AUTHOR(S)

Mammadova Shalala Adishirin

Mammadova Shalala Adishirin. (2021) The Investigation of the Grammatical and Lexical Polysemy in the Comparative

ARTICLE INFO Languages. International Journal of Innovative Technologies in Social Science. 4(32). doi:

10.31435/rsglobal_ijitss/30122021/7736

DOI

https://doi.org/10.31435/rsglobal_ijitss/30122021/7736

RECEIVED

30 October 2021

ACCEPTED

18 December 2021

PUBLISHED

22 December 2021

LICENSE

This work is licensed under a Creative Commons Attribution

4.0 International License.

(C) The author(s) 2021. This publication is an open access article. 


\title{
THE INVESTIGATION OF THE GRAMMATICAL AND LEXICAL POLYSEMY IN THE COMPARATIVE LANGUAGES
}

\author{
Mammadova Shalala Adishirin, Odlar Yurdu Universitety (OYU), Baku, Azerbaijan
}

DOI: https://doi.org/10.31435/rsglobal_ijitss/30122021/7736

\section{ARTICLE INFO}

Received 30 October 2021

Accepted 18 December 2021

Published 22 December 2021

\section{KEYWORDS}

Social Media, Digital evaluation, digital use, digital relations, internet use.

\begin{abstract}
The issue of investigation of polysemy is one of the actual problems in the linguistics. Words are realized in relation to each other (nouns in certain areas, or verbs with adjectives, nouns), and can serve to express a certain meaning. Therefore, to study the semantic nature of words, we can rely on contextual analysis, follow it as a fact of language and speech, and as a result, we can see that words have different meanings in language. Models in terms of having common-integral properties (semantic-grammatical) of the set of words in the dictionary, which creates a linguistic picture of the objective world, are grouped in certain areas in the form of subsystems, and these areas are separated from each other by different colored "borders" on the dictionary map on the basis of paradigmatic features. The set of words in each field can fall into a certain "normal" syntagmatic processing environment, which is regulated by different linguistic features. For words in the "foreign" field, any word exceeds the normal parameter of the set that enters. Its field When it falls into the normal working environment, syntactic and logical environment, the language unit acquires a new property, polysemy or poetism emerges. In the world of "reality", the world of "language" does not coincide with each other, there is no correspondence between them, so in linguistic semantic analysis the "linguistic landscape of the world" is studied.
\end{abstract}

Citation: Mammadova Shalala Adishirin. (2021) The Investigation of the Grammatical and Lexical Polysemy in the Comparative Languages. International Journal of Innovative Technologies in Social Science. 4(32). doi: 10.31435/rsglobal_ijitss/30122021/7736

Copyright: (C) 2021 Mammadova Shalala Adishirin. This is an open-access article distributed under the terms of the Creative Commons Attribution License (CC BY). The use, distribution or reproduction in other forums is permitted, provided the original author(s) or licensor are credited and that the original publication in this journal is cited, in accordance with accepted academic practice. No use, distribution or reproduction is permitted which does not comply with these terms.

Introduction. In learning and tracking polysemy is of great importance as noted in the linguistic literature, it is as if the "language net" is drawn over the world of reality, and a linguistic picture of the objective world, or a peculiar reflection of reality in language, emerges.

This reflection is materialized not in individual words, but in different texts arising from the regular connection of words. The processes of thinking that take place on the basis of objects and events of both the individual verb and the objective world find their materiality in the majority of texts. And for linguistic semantics, the "meaning text" approach is of particular interest.

Scope of Study. The Scope of study explores the interrogation of polysemy Without denying the phono-morphological, in a sense, semantic denotative independence of the verb, it must be said that the semantic informative (communicative) reality of any word (mono or polysemantic) is only a text, a sentence opens up within the expression, gains certainty, and for semantic analysis the semantic aspect arising from the internal relations of the various signs between the different types of meanings comes to the fore. Therefore, going beyond the "meaning-text" chain in semantic descriptions turns linguistic analysis into encyclopedic descriptions. The polyfunctionality that demonstrates the richness of the language's expressive possibilities, the configurative nature of the word, and its intransigence can be eliminated only in artificial languages. 
Research Methodology. For the successful realization of the goal of the investigation of the polysemy, a number of methods and linguistic analysis mean including structural semantic and methods of contextual analyses have been used.

The investigation of the Grammatical and Lexical Polysemy in the Comparative languages.

The problem of ambiguity in language is very complex and is directly related to the problem of homonymy. Indeed, a phonetic and orthographic complex expresses several objects, qualities and signs, various processes, express different signs and aspects of processes.

The meaning of the verb is a very complex and broad concept. If we look at verbs with different meanings, we see that their meanings have an unusually complex system. Bite - 1 . bite 2 . eat, light snack 3. go on a trip with someone. Clearly, language units, including verbs, can be studied in various aspects, even as an abstract phenomenon, isolated from the general system of language. However, no matter how important this research is as an evolution of general theory, it will be deprived of its fields of application because it does not rely on the reality of language, the real activity of verbs in language. It is no coincidence that in linguistics, when speaking of language and speech, two forms of speech are mentioned: 1. Productive speech; 2. Receptive speech. The speaker's speech is called productive speech, that is, the idea is clear, the form that expresses it, the material shell is unknown. Indeed, any individual knows the idea he wants to convey in the form of internal speech with all its precision and breadth; The extent to which he conveys an idea known to him to the listener will depend, firstly, on the speaker's ability to choose the most appropriate one from the many forms (combinations) available, and secondly, on the listener's level of perception of that idea. The listener's speech is called receptive speech. In this form of speech, on the contrary, the form of thought (word, sentence, grammatical forms) is known, the content is unknown. Therefore, the term meaning is a broad concept and, in our opinion, is a fact of language. Verbs therefore express themselves as expressions of a specific object when they are associated with another group of words in a particular speech setting. Different semantic words (noun, adjective, verb) act together as a fact of speech, they are united according to a single law of the general system, and in the course of these combinations they help each other to become a unit of communication.

The fact that words with different semantics in a language are sometimes used in "abnormal" contextual conditions and that different languages serve to express foreign relations is related to the general nature of the thought process. one point:

Semantic innovations in different contexts seem to demonstrate thought-language adequacy at

The bulging of any of the words has a communicative function it emerges under certain speech conditions, and this revelation is perceived each time as a fact of new content.

In fact, the polysemantic nature of this process-word, as mentioned above, occurs as a result of the multi-component nature of the concept.

This or that word realizes its semantic-communicative reality in connection with a certain group of lexical units, the fact that he found it in a special syntactic environment, in our opinion, gave rise to such an idea, which is not true.

In addition, the development of a word, especially a polysemantic word, in a certain syntactic environment, its connection with different lexical and grammatical units, determines its communicative value, enters the word from the syntactic sphere to the dynamic sphere and transforms it into an element of a new mechanism.

As for the activity and development of the word in different contexts, they always appear as an individual, unique feature of the word.

Whether the general possible meanings of a word or its meaning in a specific context becomes a fact of communication depends on its function at the functional level and in this sense it is difficult to speak of the semantic value of the word separately.

However, this specific feature does not overshadow the reality and materiality of the word as a fact of language and speech.

Arnold I.V. said that the invariability of these stages at all stages of the emergence and development of language (epic threshold) to live the conclusions of the past, makes the dialectic of creating new (ethical limits) possible, eliminates the need for a radical change of language in the change of generations. 
In its development, language is constantly enriched with new concepts and new words. It should be noted that new concepts in language are not always expressed in new words. In some cases, new concepts are internal semantic potentials that exist in the language, it is realized at the expense of internal resources, and thus there is a transfer of meaning or polysemy. Polysemy, or semantics, is semantically universal and is common to many languages. Polysemy is a very complex and controversial problem that has attracted the attention of researchers in Azerbaijani linguistics, Turkology, Russian and German studies some features of this problem have been described. In this regard, it should be noted that the comparative study of polysemy based on the material of languages belonging to several different systems it will help to show more clearly the essence of this category, its development, and the factors that create it.

At the same time, according to D.A. Cruise, this type of research will show the universality of human thought, the similarity of semantic universals and human experience.

Language, which is a means of expression of thought, is a social phenomenon. This is also related to other social events. However, language is not like other social events in all respects. It has its own characteristics. The main characteristic of language is that it has not been the product of a few years or a certain period, but of centuries It is gradually formed and enriched through the process of development.

Also, without making any distinction between the members of the society he has served since the creation of the language it is an equal means of communication for all members.

Therefore, the language has a social character. Language is organically connected with the history of the people, because language is formed only within society. It is the people who create the language. That is why the fate of language depends on the fate of the people who created it. After creating their own language for communication, each nation preserves and develops it throughout history. meaning.

Changes that occur historically after the original meaning of a word are called changes in its

Changing the meaning of each word does not happen by itself. This is, first of all, the sociopolitical structure of this or that society, the worldview of the society and so on. It is a process going on in connection with. Therefore, the meaning of the word is often changed. The frequency of polysemy in different languages depends on various factors. In what language is the process of word acquisition and complex word formation widely used the language tends to fill in the gaps in the vocabulary by adding new meanings to existing terms. The phenomenon of polysemy occurs in general words rather than special words.

Semantic changes are divided into two groups:

1) extra-linguistic and 2) linguistic reasons.

Extra-linguistic reasons are changes in the speech society, the economy and changes in social composition, ideas, scientific concepts, lifestyles, and changes in other spheres of human activity are envisaged. Linguistic reasons are related to changes in the language system. The most noticeable form of these effects are ellipses in a two-word expression, one word is omitted and the meaning is transferred to the other. In Old English, the verb to starve meant "to die" and was used interchangeably with the word hunger (ME. sterven of hunger). In the 16th century, the verb changed to starvation. In other words, a word is singular as a unit of speech and ambiguous as a unit of language.

In speech, the word moves away from additional shades, but is understood in a basic sense. The word does not refer to the thing in the main sense due to several features, is reinforced and understood according to a sign.

He expresses only one version of himself in his speech. Of course, it does not preclude the breadth and complexity of contextual meaning for a word to be unambiguous in speech.

On the contrary, it creates conditions for its clarification and differentiation. The tendency of a word to be monotonous in the exchange of ideas and in the process of speech is reminiscent of its first appearance.

The choice of words according to their meaning and different shades of meaning depends on the degree to which the meanings of those words correspond to the object or event.

Words in a language are not the same in quantity or degree of meaning. Thus, some words have one meaning and some words have several meanings. Based on this, the phenomenon of uniqueness arises in the lexical-semantic system of language. Some words do not fully reflect an object or event, but only in one sense. The fact that words express only one meaning is called monosemy (mono - single; sema - sign). Indeed, a phonetic and spelling complex expresses several 
objects, qualities and signs, various processes, expresses different signs and aspects. For example, the rear (human and animal limbs, backs, limbs, backs and the back of the front line during the war, space, help, patron, support, protector); class // audienc (classroom and a certain group of people); buy (take, raise // buy and hold rank, title, rank, seize, conquer), etc. So it has the ability to act as the name of many different things and events. The use of the word in several senses does not cause any misunderstanding during communication. Because the meaning of the word is always clarified and clarified through the text, the context. It is the text that reveals that the word has different meaning in speech, the word always appears in one of its meanings. The text defines and clarifies the meaning of the decisive role of the text in the emergence of this or that meaning of the word was highly appreciated by M. Bromberg over time: "The meaning of a word is always determined by the text. Despite the fact that the word has different meanings, it is the text that specifies its "special" meaning. The concept of ambiguity implies that a word has a complex semantic system, in addition to its primary meaning, it also has several secondary meanings. In this regard, it should be noted that while a group of scholars call secondary meanings figurative meanings.

Sh.A. Mammadova, M. Adilov, S. Jafarov others, considering the fact that each of these meanings has the ability to have a separate figurative meaning, evaluate them as secondary meanings (K.A. Allendorf, S. Jafarov). This diversity of opinion is explained by the complexity of the semantics of the ambiguous word. It is known that the figurative meaning of a word is formed on the basis of its original meaning, i.e. nomative meaning, and thus acts as the core of other meanings in the language. The existence of a figurative meaning is impossible without a nominative meaning. Figurative meaning always derives from the main meaning and depends on it. For example, the basic meaning of the word ambiguous goal in the Azerbaijani language is clear, even without the text. As a result of the similarity, the word arm can also act as the name of another object. For example, the sleeve of a shirt, the sleeve of a tree, and so on. These meanings derive from the nominative meaning of the word arm and form the semantic structure of that word. Other examples: The verb to carry has one primary meaning and several secondary meanings:

Carrying something from one place to another, carrying it (carrying a suitcase).

1) To direct someone's movement, to show the way: to help him walk with himself (to take children to the theatre).

2) Take it with you (the bad one was washed away).

3) Stealing, kidnapping (the jackal took the chicken).

4) Figuratively: to win, to win, to win (to play a game).

Figuratively: to destroy, wipe clean, remove (remove stain).

5) Figuratively: to destroy, to annihilate, to ruin, to spoil, to destroy (carried the hail of fruit).

6) To cause to be spent, to be processed, to take away (this work took five days).

7) Figuratively: tearing, eating, cutting, rubbing, spoiling (took the bottom of the stone razor).

8) Implement, implement (work).

9) To manage, to lead, to lead, to lead (to hold a meeting).

10) Figuratively. Anesthesia, intoxication (drowsiness, numbness, took the patient medication).

Polysemy, by its very nature, is the product of generalization in language. Polysemy manifests itself in many languages and acts as a semantic (static) universality. However, it should be noted that in some languages, such as the languages of the Australian aborigines, which are considered agglutinative, ambiguity is expressed more weakly and simply than in Azerbaijani, English and Russian. For example, in the Aranda language, which has a vocabulary of 10,000 words, the generalization is very weak, so there are many words denoting concrete things, but words denoting abstract concepts are almost nonexistent. For example, while there are many animal names in this language, there is no word for a common animal. Thus, in these languages, of course, ambiguity is poorly developed. Let's look at the semantic development of the words "buy" and "clear" used in modern Azerbaijani.

Conclusions. The results giants from the discussed issues in the separately-taken branches of the study can be generalized as follows:

There are also different views on lexical and grammatical polysemy in Russian and English literature.

1. The views expressed in some of these sources coincide with those of our linguists, while others are completely different. Rayevskaya N.M. accordingly, words that are different in meaning but similar in grammatical meaning can be called homoform. 
2. The existence of homoforms in different languages is due to the analytical and synthetic features of their structure, and their study is grammatically interesting. Rayevskaya N.M, English Lexicology. Kiev, 1979, p. 2020. 1. Bound (to bound) - jump, run with jumping movements - (jump).

Bound - past and past participle of to bind - to fasten together and put a cover on the pages of a (book) - (bind, bind).

2. Ground - past and past patciple of to grind - crush to powder.

O.O. Jesperson included this group of verbs in the group of simple lexical-grammatical homonyms. As we have seen, the same formal words have been assigned to different groups by different linguists. This situation has arisen because they use different criteria in the classification of homonyms.

Arbekova T.I. noted different examples of homoforms. According to him, rose is homoform in the sentences "a red rose" and "the sun rose". These words refer to different parts of speech. In sentence 1 , rose is a noun, and in sentence 2 , it is a past tense form of the verb "to rise." Some Azerbaijani linguists have described homoforms in this way. 1. Tide (noun) - regular rise and fall in the level of the sea (swelling, retreat)

Tied - past and past participle of to tie - fasten or bind with string.

2. His burns will take a long time to heel.

Paper burns easily. In the first sentence, "burn" is a noun and has taken the -s suffix denoting quantity. In the second sentence, it is used as a verb and takes the suffix -s, which means the third person singular. In addition, Arbekova TI included in the list of homoforms homonyms, which are corrected by the transition of parts of speech to each other - by conversion. For example:

Hope (noun) - desire and expectation that something good will happen (hope)

You are every reason, every hope, every dream I have ever had.

Hope (verb) - desire an expect

That's what I hope to give to you forever.

3. Homonyms formed from polysemous words. Homonyms formed from ambiguous words are a gradual process. Derivatives of ambiguous words differ from words of lexical and grammatical meaning. In polysemous words, different meanings are directly related to the main meaning, but sometimes there is a big difference between the newly formed meaning and the main meaning, and homonymous words are formed. Polysemous words are fragmented due to archaic, falling, and other reasons. In the dictionaries of V.K. Müller, Hornby and V.D. Arakin, the word "spring" is approached from a different perspective. Thus, Müller and Hornby have two different meanings of this word: 1.A season of the year; 2.a) The act of springing, a leap b) a place where a stream of water comes up out of the earth, while Arakin took the three mentioned meanings separately. (Antrushina G.B, Afanaseva O.V., Morozova N.N., English Lexicolog, M, 2001, p. 34). Homonyms formed as a result of derived words. Derived words form a certain part of the vocabulary of the language. Some of these words together with national words form homonymous lines. These homonymous lines consist of either a whole - a mixture of words, or a mixture of national words. For example:

Boil -1) verb. To boil water, making it bubble and steam. Derived from the French words boilir, builir.

1) noun. (Native) An unpleasant and painful swelling on the skin.

Curtain -1) noun- differentiation of sounds on stringed musical instruments (Persian)

Curtain -2) noun-cover (Persian)

Curtain -3) noun - act, action in the work (Persian)

Squash -1) Noun. An eatable fruit of the gourd family which is served as a vegetable. It was first used in 1643.

2) Noun. A ball game played by two players with racquets - 19th century English.

3) Noun. A type of drink made with fruit juice and water - 19th century English.

4) Verb. Compress, crush, squeeze tight - from the word esquasser of French origin.

I.V. Arnold noted that a word passes from one part of speech to another either through certain grammatical features or without any grammatical index. Which part of speech a word without a formal index belongs to is determined by its lexical and grammatical meanings and syntactic functions. 


\section{REFERENCES}

1. Abdullayev, A. Text comprehension models / A.Abdullayev - Baku: - 1999. - 345p.

2. Adilov, M. Detailed linguistic terms / - M.Adilov, Z.Verdiyeva, F.Agayeva. - Baku: Elm, - 1989. - 358 p.

3. Akhundov, A. General linguistics / A.Akhundov. - Baku: Maarif, 1988. - 280 p.

4. Bayramov, H. Basics of phraseology of the Azerbaijani language / H.Bayramov. - Baku: Maarif, - 1978. - 174 p.

5. Jafarov, S. Word creation in the Azerbaijani language / S.Jafarov. - Baku: AUL, - 1960. - 203 p.

6. Hajiyeva, A. Najafli E. Contrasive Lexicology / A. Hajiyeva. Najafli E. - Baku: - 2010.

7. Mammadov, A. Text linguistics / A.Mammadov. - Baku: - 2001. - 56 p.

8. Mammadova, Sh.A. Thoughts on polysemy / - Baku: Scientific works (Language and literature series), 2019. № 2, - p.65-69

9. Admoni, V.G. Fundamentals of the theory of grammar / V.G.Admoni. - M: - L. Science, - 1964. - 104 p.

10. Alekperov, A. Lexical semantics of simple verbs in the modern Azerbaijani language // A. Alekperov. Baku: Elm, - 1983. - 160 p.

11. Alieva, G. Semantics and pragmatics of derivative words and identification of their relationship with cognitive components // G. Alieva - Baku: - 2016. - 167 p.

12. Antrushina, G.B. From the history of words in their meanings / G.B. Antrushina. - Moscow: Science, 1960. - from.

13. Arakin, V.D. History of the English language / V.D. Arakin. - Moscow: Publishing House Education, 1985. - $256 \mathrm{p}$.

14. Arbekova, T.I. Lexicology of the English language / - Moscow: Higher school, - 1977. - 240 p.

15. Арнольд, И.В. Лексикология современного английского языка / И.В. Арнольд. - Москва: Издательство Высшая школа, - 1986. - 350 с.

16. Balazh, J. Syntagmatization and lexicolization (on the theoretical issues of lexicology and lexicography). Lexicology and lexicography / J. Balazh. - Moscow: - 1972.

17. Vinogradov, V.V. Basic types of lexical values. Questions of linguistics / V.V. Vinogradov. No. 5.- 1953. - 260 p.

18. Gak, V.G. To the problem of semantic syntagmatics. Problems of structural syntagmatics / V.G. Gak. Moscow: Science, - 1972. - p.

19. Saussure, F. de. General linguistics course [2] / F. de Saussure. - Moscow: Progress, - 1977. - 696 p.

20. Antrushina, G.B. and others. English lexicology. M: - 1985, - 219 p.

21. Arnold, I.V. The English Word / - M: - 1986, - 295 p.

22. Bromberg M, 504 Absolutely Essential Words. / J. Libb and A. Traiger - New York: Barron's, - 2012. - 202 p.

23. Cruse, D.A. Lexical Semantics / D.A. Cruse, New York: Cambridge University Press, -1986, - 310 p.

24. Collins English dictionary / Publishers: Harpercollins. - 1994. - $1791 \mathrm{p}$

25. Gough C. English Vocabulary Organizer. The UK, Commercial Color Press plc, - 2003, - 224 p.

26. Jesperson O. A Modern English Grammar on Historical Principles. Copenhagen, - 1949, - 512 p.

27. Longman Lexicon of contemporary English / Longman - 1996, - 910 p.

28. Rayevskaya N. English lexicology / N. Rayevskaya - Kiev: - 1957. - 169 p .

29. Zeynalli M., Gezalova K. Word formation in English / M. Zeynalli, K. B. Gezalova. - 2005. - 114 p. 